\title{
Characterization and modelling of both high-cycle high- temperature fatigue behaviour of Stainless Steel Grades
}

\author{
Pierre-Olivier Santacreu ${ }^{1, *}$ Cloé Prudhomme ${ }^{1}$, Benoit Proult $^{1}$ and Isabelle Evenepoel ${ }^{1}$
}

${ }^{1}$ APERAM, Centre de Recherche, 62330 Isbergues, France

\begin{abstract}
In the same context of thermo-mechanical fatigue and high temperature applications of stainless steel, high-frequency vibration fatigue at high temperatures should be considered, in particular for automotive exhaust gas applications. In fact one of the most frequent incidents that can happen on exhaust components is an accumulation of low-cycle thermal fatigue and high-cycle fatigue. The prediction of the lifetime of a structure under such complex thermal and mechanical loading is therefore a constant challenge at high temperature due to the coupling of metallurgical, oxidation or creep effects. In order to better understand in a first approach, the high cycle fatigue of stainless steels at high temperatures, tractioncompression tests were performed on flat specimens at $25 \mathrm{~Hz}$, under air and in isothermal conditions from ambient temperature to $850^{\circ} \mathrm{C}$. Two different stress ratios, $\mathrm{R}=-1$ and 0.1 , are characterized with the objective to assess a multiaxial model for high temperature. Different criteria are used to predict the ruin of a structure under high-cycle fatigue but in general for ambient-around temperatures. In particular, multiaxial and stress-based DangVan criterion is today widely used to evaluate the risk of fatigue cracks initiation and it has been implemented recently in our fatigue life processor Xhaust_Life $\mathbb{R}$. Therefore the Dang Van criterion was identified from the isothermal high cycle fatigue using the 2 stress ratio and its validity is discussed especially for temperatures higher than $500^{\circ} \mathrm{C}$ where strain rate and creep effects have increasing influence. Results are presented for two ferritic stainless steel grades used in high temperature exhaust applications: K41X (AISI 441, EN 1.4509) and K44X (AISI 444Nb, EN 1.4521).
\end{abstract}

\section{Introduction}

Endurance fatigue is one of the most current damage modes of component subjected to cyclic loadings, especially in transport (automotive, railway rollingstock, aviation). For most of these applications, life prediction is a mandatory requirement and implies the determination of endurance limit and S-N curves. Because a structure is subjected to multiaxial loading, fatigue tests need to be carried out at minimum two stress ratios, generally at $\mathrm{R}=-1$ and $\mathrm{R}=0.1$, in order to take into account of this effect. In general room temperature endurance data are available to most standardized grades but less for high temperature (HT) conditions and different stress ratio conditions. High temperature fatigue is also often studied at low frequencies by Low-cycle fatigue using strain controlled test. On the other hand in many high temperature applications, the study of the thermomechanical or thermal fatigue makes more sense when a thermal cycle is applied on a constrained structure or when it is added to the cyclic loading. Finally in many real situations, accumulation of different types of high temperature damage processes has to be considered. Example of the exhaust manifold parts illustrates that situation where a coupling between thermo-mechanical fatigue, vibration fatigue and creep is often observed.

Several references are already available on the TMF of exhaust manifold [1-3]. In the present paper we are looking for both high temperature and high cycle fatigue in range from the ambient temperature to $850^{\circ} \mathrm{C}$ on two stabilized ferritic stainless steel grades for HT applications K41X (AISI 441, EN 1.4509) and K44X (AISI $444 \mathrm{Nb}, \mathrm{EN} 1.4521$ ) already presented in [4,5].

Multiaxial modelling of $\mathrm{HCF}$ is suitable for virtual design approach. In automotive, Dang Van criterion is very popular and has demonstrated its scientific relevance especially in automotive design [6]. However it is not so applied for HT, even if a tentative extension for non isothermal was proposed in [7]. On our side we have evaluated opportunities to apply multiaxial criterion including the Dang Van one.

\section{Materials and Experimental Procedure}

\subsection{Ferritic stainless steel for high temperature applications}

Ferritic stainless steels are chromium steel (AISI 400 series) containing a minimum of $11 \% \mathrm{Cr}$ to ensure a 
proper corrosion resistance. Among ferritic stainless steel, grades used for high temperature applications are for most of them $\mathrm{Ti}$ or $\mathrm{Nb}$ stabilized grades and exhibit at least $15 \% \mathrm{Cr}$. Such chemical composition guaranties a stable microstructure for a large range of temperature and an improved oxidation resistance. Ferritic grades have also low coefficient of thermal expansion around $12.10^{-6} /{ }^{\circ} \mathrm{C}$ compared to $19.10^{-6} /{ }^{\circ} \mathrm{C}$ for refractory austenitic stainless steel. For all these reasons ferritic stainless steel grades are good candidates for high temperature applications like automotive exhaust systems, burner or solid oxide fuel cell interconnector.

The present study is focusing especially the AISI441 1.4509 (Aperam K41X) and an improved AISI 444Nb 1.4521 with $19 \% \mathrm{Cr}$ and $\mathrm{Nb}$-stabilized (Aperam K44X). Their compositions are given in Table 1. All tests presented hereafter have been carried out on flat samples in a standard 2B or 2D metallurgical state (cold rolled and annealed), with thickness between 1.5 and $2 \mathrm{~mm}$.

Table 1. Chemical Compositions in $w \%$ of the two ferritic grades studied in the present paper.

\begin{tabular}{|l|l|l|l|l|l|l|l|}
\hline Grade & $\mathbf{C}$ & $\mathbf{C r}$ & $\mathbf{S i}$ & $\mathbf{M n}$ & $\mathbf{M o}$ & $\mathbf{N}$ & Other \\
\hline $\begin{array}{l}\text { K41X-1.4509 } \\
\mathbf{4 4 1}\end{array}$ & 0.02 & 17.8 & 0.6 & 0.3 & - & 0.015 & $\mathrm{Ti}+\mathrm{Nb}=0.6$ \\
\hline $\begin{array}{l}\text { K44X -1.4521HT } \\
\text { 444Nb }\end{array}$ & 0.02 & 19 & 0.6 & 0.3 & 1.9 & 0.015 & $\mathrm{Nb}=0.6$ \\
\hline
\end{tabular}

\subsection{Tensile tests}

High temperature tensile tests were carried out according to EN ISO $6892-2$ standard on a $100 \mathrm{KN}$ INSTRON tensile machine with a $1000^{\circ} \mathrm{C}$-resistance furnace (Fig.1). Specimens are cut in rolling direction. In general two or three samples are tested per condition. After a $2 \mathrm{~h}$ heating procedure, tensile tests were performed at a constant displacement rate of $0.54 \mathrm{~mm} \mathrm{~min}^{-1}$.

\subsection{High-Cycle fatigue tests}

Endurance fatigue tests are carried out at high frequency $(25 \mathrm{~Hz})$ under stress control. About 20 samples need to be tested to draw a fatigue S-N curve (or Wohler curve) and to determine the endurance limit at 2,000,000 cycles. In order to access a fatigue analysis of structural under multi-axial loadings, two stress ratios are selected: tensile-compression at $\mathrm{R}=-1$ and alternating tension at $\mathrm{R}=0.1$ where $\mathrm{R}$ is defined by:

$$
R=\frac{\Sigma_{\min }}{\Sigma_{\max }}
$$

Specimen preparation is a major step and must be carefully done. Specimen geometry is taken in rolling direction and machined by milling with polishing of the edges. Because of the large quantity of results required for each condition, fatigue tests are subcontracted to METCUT SA that carried out these tests according to ASTM E-606-97 standard on a $100 \mathrm{kN}$ MTS fatigue machine. Temperature during the test is achieved by induction heating (Fig.2). Statistical data treatment performed at Aperam Research Center consists in determination of the endurance limit by the stair-case method and in fitting of the fatigue curve by different models (Wohler, Bastenaire, etc) with the help of ESOPE software.

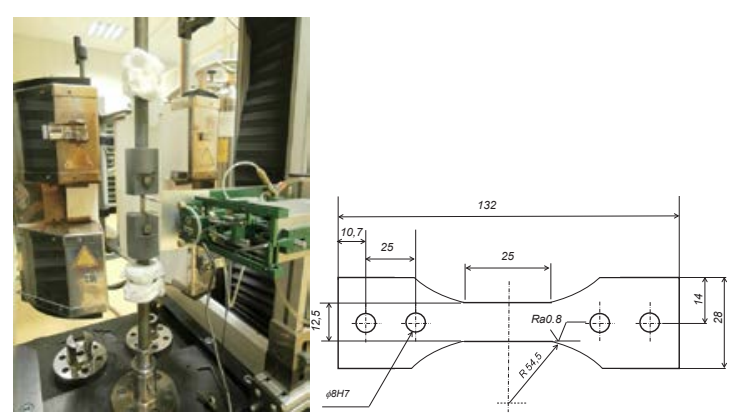

Figure 1 tensile test at high temperature: set-up on left, specimen geometry on right
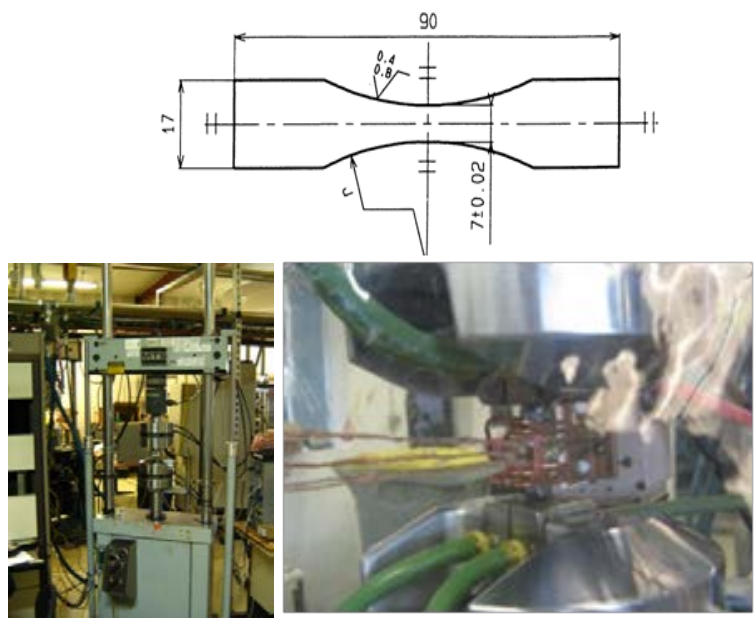

Figure 2 high-cycle fatigue at high temperature: specimen geometry on top and fatigue machine with induction heating (courtesy of METCUT)

\subsection{Creep tests}

Isothermal uniaxial creep tests are performed with an INSTRON 8802 tensile machine. Specimens are submitted to constant load while their deformation is monitored thanks to a high temperature extensometer up to $1 \%$ of creep strain. Tests are performed on flat specimens, cut along the rolling direction, between 750 and $950^{\circ} \mathrm{C}$ and up to $100 \mathrm{~h}$.

\section{Experimental Results}

\subsection{Strengths and Endurance limits}

Tensile properties evolution of ferritic stainless steel in function of the temperature is well illustrated on Fig. 3 on the K44X $444 \mathrm{Nb}$. Tensile strength and yield stress are dropping sharply after $600^{\circ} \mathrm{C}$. At the reverse, elongation is increasing rapidly due to a striction of the specimen. 
Fatigue limit are expressed by maximal fatigue strength $\Sigma_{\max }^{D}$ at $2,000,000$ cycles but can be related to the stress amplitude $\Sigma_{\mathrm{a}}$. Results obtained for temperature in range from room temperature to $850^{\circ} \mathrm{C}$ are given in Table 2 and are shown on Figure 4. It could be noticed that endurance limits for $\mathrm{R}=-1$ and $\mathrm{R}=0.1$ are crossing each other at around $650^{\circ} \mathrm{C}$ and so endurance limits in tensile-compression are becoming higher than endurance limit in alternating tension.

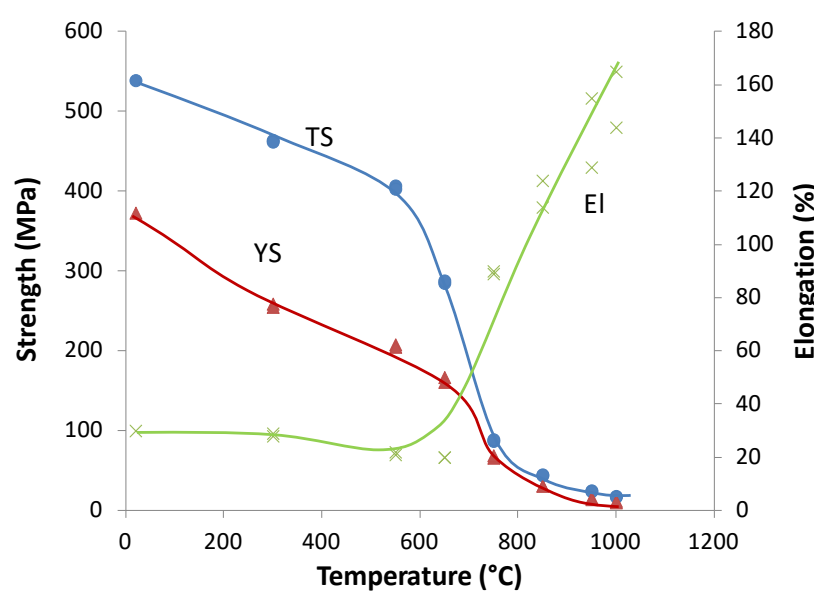

Figure 3. Tensile properties (TS, YS and El) in function of temperature for K44X-1.4521HT-444Nb

Table 2. Endurance limits $\Sigma_{\max }^{D}$ in MPa at 2,000,000 cycles in function of temperature.

\begin{tabular}{|l|l|r|r|r|r|r|}
\hline Grades & $\mathbf{R}$ & $\mathbf{2 3}^{\circ} \mathbf{C}$ & $\mathbf{3 0 0}^{\circ} \mathbf{C}$ & $\mathbf{6 5 0}^{\circ} \mathbf{C}$ & $\mathbf{7 5 0}^{\circ} \mathbf{C}$ & $\mathbf{8 5 0}^{\circ} \mathbf{C}$ \\
\hline \multirow{4}{*}{$\mathbf{4 4 4 N b}$} & & 485 & 452.5 & 98.3 & & 43.7 \\
& 0,1 & $(6.9)$ & $(0.2)$ & $(4.1)$ & & $(1.8)$ \\
\cline { 2 - 7 } & & 312.5 & 265 & & & 66.2 \\
& -1 & $(11.6)$ & $(0.5)$ & $100(4.5)$ & & $(1.7)$ \\
\hline \multirow{4}{*}{441} & & 433 & 406.5 & & 47.5 & 17.5 \\
& 0,1 & $(9.5)$ & $(11.3)$ & & $(12.4)$ & $(0.2)$ \\
\cline { 2 - 7 } & & 282.5 & 244.5 & & 459 & 40.5 \\
& -1 & $(3.5)$ & $(7.4)$ & & $(1.4)$ & $(0.1)$ \\
\hline
\end{tabular}

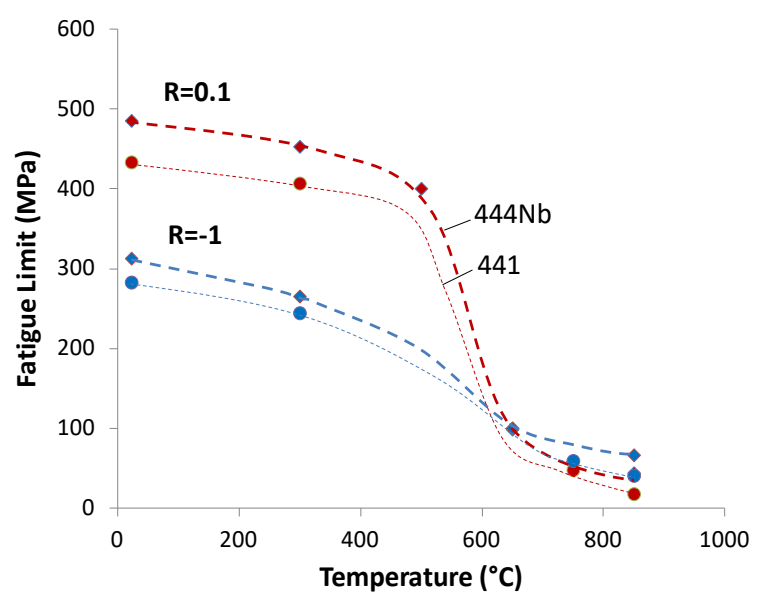

Figure 4 Endurance limit at 2,000,000 cycles, for $\mathrm{R}=-1$ and $\mathrm{R}=0.1$ in function of temperature for the 2 ferritic grades

\subsection{Effect of temperature on fatigue to tensile strength ratio}

The ratio between endurance limit and tensile strength is often calculated because it gives a constant value only dependent on steel family. This is true at room temperature but what happen when temperature is increasing?

For temperature range from room temperature to $\sim 500^{\circ} \mathrm{C}$ fatigue strength ratio remains stable: $0.9-1$ for $\mathrm{R}=0.1$ and $0.5-0.6$ for $\mathrm{R}=-1$. These values are well correlated with usual values obtained on steels with a CC structure. For temperature high than $750^{\circ} \mathrm{C}$, fatigue limit is affected by viscous effect, evidenced by a fatigue ratio greater than 1, i.e. a fatigue limit higher than tensile strength as shown for $\mathrm{R}=-1$ (Fig.5). That could be surprising but tensile tests are carried out at low strain rate compared to HCF tests. Another interesting point already mentioned is the crossing of fatigue strength for the two stress ratio. The phenomenon can be attributed to a mean stress effect. Especially at $\mathrm{R}=0.1$, fatigue fracture is linked with a severe necking of the sample area. For example, recorded measure of elongation on 441 sample gives $7 \mathrm{~mm}$ after $15 \mathrm{~h}$ of $\mathrm{HCF}$ test at conditions $25 \mathrm{~Hz}, 850^{\circ} \mathrm{C}$ and $20 \mathrm{MPa}$. In between at temperature around $650^{\circ} \mathrm{C}$ situations is more confusing due both viscous and both strain and precipitation hardening effect. In fact in that range of temperatures stabilized ferritic grades exhibit a precipitation of $\mathrm{Fe}-\mathrm{Nb}$ intermetallics in aim to improved creep resistance.

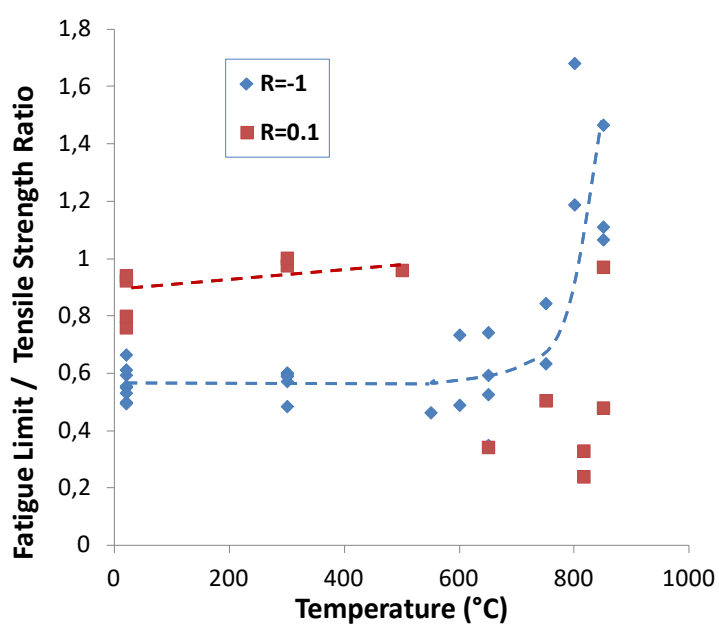

Figure 5 Ratio of fatigue limit on tensile strength for different stainless steel grades including 441 and $444 \mathrm{Nb}$

\section{Multi-axial fatigue modelling}

\subsection{From Haigh-Goodman to Dang Van Criterion}

In first empiric approach, Haigh-Goodman diagram [8] can be drawn for the different temperature using stress amplitude $\Sigma_{a}^{D}$ versus mean stress $\Sigma_{\text {mean }}^{D}$ calculated from: 
$\Sigma_{a}^{D}=\frac{1}{2} \Sigma_{\max }^{D}(1-R)$

$\Sigma_{\text {mean }}^{D}=\frac{1}{2} \Sigma_{\max }^{D}(1+R)$

The higher the temperature, the quicker the line rotation due to the more pronounced mean stress effect. Value of stress to creep fracture $\Sigma_{\mathrm{c}}$ for approximatively $20 \mathrm{~h}$ (duration of the HCF test) are reported on mean stress axis for the 441 at $750^{\circ} \mathrm{C}$ and $850^{\circ} \mathrm{C}$. They are quite relevant with fatigue limit at $\mathrm{R}=0.1$ and confirm that creep mean stress effect is dominant at high temperature.

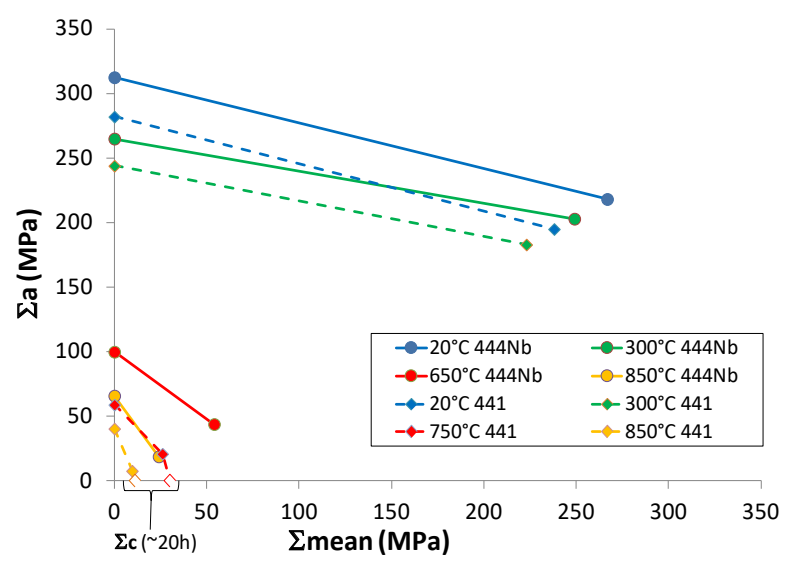

Figure 6. Haigh-Goodman diagram in range of temperatures from ambient to $850^{\circ} \mathrm{C}$

An extension of macro-meso Dang Van approach can be established in case of isothermal or non-isothermal cyclic loadings. But it stipulates a local shakedown condition and so both mesoscopic residual stress $\rho^{*}$ and plastic strain fields are independent of time. Therefore the fatigue criterion is expressed as a linear combination of local shear stress and hydrostatic stress at mesoscopic scale defined by:

$\tau(t)=\frac{1}{2} \cdot \Sigma_{a} \cdot\left|\sin \left(2 \pi \cdot \frac{t}{\tau}\right)\right|$

$p(t)=\frac{1}{3}\left(\Sigma_{\text {mean }}+\Sigma_{a} \cdot \sin \left(2 \pi \cdot \frac{t}{\tau}\right)\right)$

At endurance limit the two quantities reach their maximal value, and the famous Dang Van line can be drawn from the two stress ratios fatigue results:

$$
\begin{aligned}
& \tau_{\max }=\frac{1}{4} \cdot \Sigma_{\max }^{D} \cdot(1-R) \\
& p_{\max }=\frac{1}{3} \cdot \Sigma_{\max }^{D}
\end{aligned}
$$

The Dang Van lines for the different temperatures are shown on Fig.7. If the approach appears to be correct for $20^{\circ} \mathrm{C}$ and $300^{\circ} \mathrm{C}$, the lines are rotating for the highest temperatures $650^{\circ} \mathrm{C}, 750^{\circ} \mathrm{C}$ and $850^{\circ} \mathrm{C}$ and the slopes are becoming positive. The hypothesis of local shakedown is definitively wrong for high temperatures.

Our proposal is to applied Dang Van criterion as long as the viscous/creep effect are weak and the ratio of fatigue limit on tensile strength is flat, i.e. up to about $500^{\circ} \mathrm{C}$ (about the third of the melting point). For the highest temperature, a new multiaxial approach appears to be necessary and based on accumulation of creep damage and HCF.

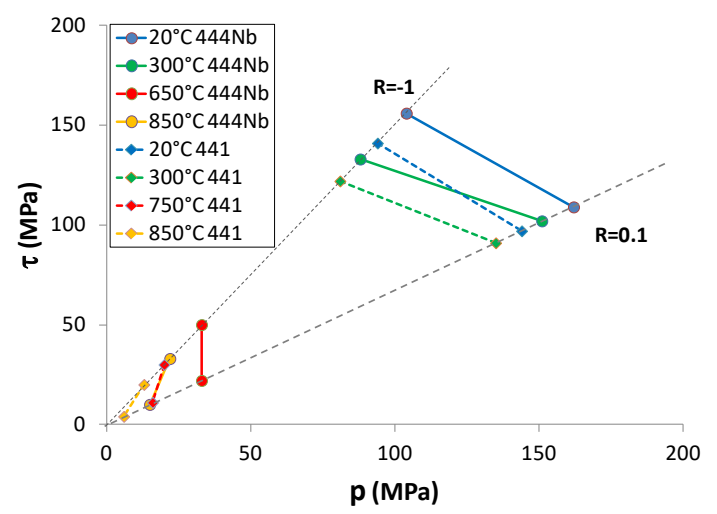

Figure 7. Dang Van diagram in range of temperatures from ambient to $850^{\circ} \mathrm{C}$

\subsection{Dang Van criterion in Xhaust_Life ${ }^{\circledR}$}

The Dang Van criterion was implemented into Aperam post processor of Abaqus, Xhaust_Life $\AA$, and then tested at low and intermediate temperatures in isothermal conditions. The mesoscopic stress field is related to the macroscopic stress field by

$\sigma(t)=\Sigma(\mathrm{t})+\rho^{*}$

Where the mesoscopic residual stress is determined according the algorithm proposed in [9]. Finally local shear $\tau(t)$ and hydrostatic stresses $p(t)$ are easily computed from $\sigma(t)$. The distance between Dang Van line at 2,000,000 cycles and local stress cycles is calculated to determine the fatigue damage. The program, which highlights the area where there is a risk of fatigue cracks initiation, has been validated on uniaxial loading (Fig.8) and tested on biaxial loading. On the other hand validation tests in both multiaxial and intermediate temperature are not yet available.

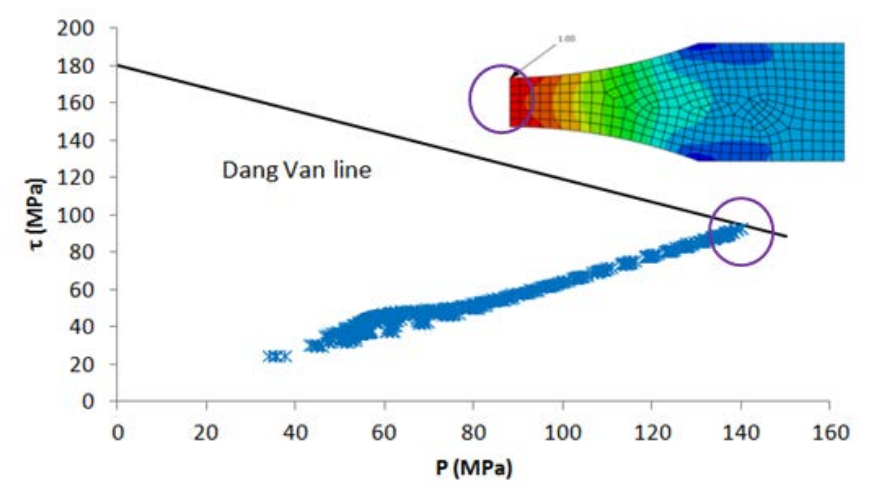

Figure 8. Example of Dang Van analysis on K41X fatigue specimen at $300^{\circ} \mathrm{C}$

\section{Discussion on a coupling with a creep damage model}


A Larson-Miller (LM) creep model is also implemented and available in Xhaust_Life ${ }^{\circledR}$ post processor for creep damage risk evaluation. A multiaxial formulation is proposed in [11] and the model relates a creep stress $\Sigma_{c}$ to a time to reach a strain of $1 \%$ given by:

$P=T .\left(\log t_{1 \%}+C\right)$

$\log \sigma_{e q}=B+m \cdot P$

Where $\mathrm{P}$ is the $\mathrm{LM}$ coefficient and $\mathrm{C}, \mathrm{B}, \mathrm{m}$ are material parameters identified from creep tests. $\sigma_{e q}$ is the multiaxial equivalent stress.

A comparison between creep stress and HCF mean stress for an equivalent duration at $850^{\circ} \mathrm{C}$ evidences quite close values and therefore confirms a major influence of the creep in HCF damage at high temperature for $\mathrm{R}=0.1$ (Tab.3).

Thus an idea could be to couple a multiaxial HCF model like Dang Van and the Larson-Miller creep model even if the accumulation rule for both HCF and creep damage has to be proposed.

Table 3. Comparison of mean stress at $\mathrm{R}=0.1$ and creep stress (in $\mathrm{MPa}$ ) to $1 \%$ elongation for same duration $\sim 20 \mathrm{~h}$ at $850^{\circ} \mathrm{C}$.

\begin{tabular}{|l|l|l|l|}
\hline Grade & $\Sigma_{\text {max }}^{D}$ & $\Sigma_{\text {mean }}$ & $\Sigma_{C}$ \\
\hline $444 \mathrm{Nb}$ & 43.7 & 24 & 22 \\
\hline 441 & 17.5 & 9,6 & 15 \\
\hline
\end{tabular}

\section{Conclusion}

Characterisations of HCF properties at high temperature were carried out at 2 stress ratios for multaxial modelling purpose. Due to viscous-creep effects, the analysis of the results for the highest temperatures, i.e. higher than $650^{\circ} \mathrm{C}$, is tricky:

- A fatigue ratio greater than 1 is observed at high temperature due to strain rate effect $(20 \mathrm{~Hz} \mathrm{HCF}$ test versus tensile test at $2 \% \mathrm{~min}^{-1}$ strain rate).

- A crossing of fatigue strength for the two stress ratios. The phenomenon can be attributed to a mean stress effect due to the creep damage.

Modelings using Goodman and especially Dang Van fatigue damage model were tested. If the Dang Van and Haigh-Goodman approach appear to be correct for $20^{\circ} \mathrm{C}$ and $300^{\circ} \mathrm{C}$, the lines are rotating for the highest temperatures $650^{\circ} \mathrm{C}, 750^{\circ} \mathrm{C}$ and $850^{\circ} \mathrm{C}$ and the slopes are becoming positive in case of Dang Van. The hypothesis of local shakedown is definitively wrong for high temperature.

Once more, the mean stress effect due to creep damage is becoming dominant at $\mathrm{R}=0.1$. So at high temperature the multiaxial HCF model must be reformulated.

\section{Nomenclature}

$\mathrm{R}$ stress ratio of high cycle fatigue test

TS tensile strength

YS yield stress

El elongation

$\Sigma \quad$ macroscopic stress field

$\sigma, \tau, p$ mesoscopic stress, shear and hydrostatic field

$\rho^{*}$ mesocopic residual stress

fatigue / endurance limit supscript

creep subscript

$\mathrm{T}$ temperature

t time

$\tau$ period of the cycle (reverse of frequency)

$\mathrm{P}, \mathrm{B}, \mathrm{C}, \mathrm{m}$ Larson-Miller parameter

\section{References}

1. Watanabe et al., Thermal Fatigue Life prediction for stainless steel Exhaust Manifold, SAE Tech paper series 980841, 1998.

2. Santacreu PO et al. Design of Stainless steel Exhaust Manifold, La revue de metallurgie-CIT, pp615-620, 2004.

3. Thomas J.J et al. Thermomechanical design in Automotive industry, Fatigue Fracture Eng. Mater Structure 27, pp887-895, 2004.

4. P.O.Santacreu, C.Simon and A.Colman, Thermomechanical fatigue behavior of Stainless steel grades for Automotive Exhaust manifold applications, $4^{\text {th }}$ vol. p.227-239 ASTM STP 1428, 2002

5. L.Faivre, P.O.Santacreu and A.Acher,A new ferritic stainless steel with improved

6. thermo-mechanical fatigue resistance for exhaust parts,Materials at High Temperature, Vol.30 (1) p.36-42, 2013.

7. K. Dang Van Comportement à la fatigue des métaux, Sciences et Techniques de l'Armement, Mémorial de l'Artillerie Francaise, p.113-116, 1973

8. H. Maitournam, T. M.L Nguyen-Tajan, Approche multi-échelle en fatigue polycyclique anisotherme C.R.Acad. Sci. Paris, t328, Série II b, p.373379,2000 .

9. Goodman J. Mechanics applied to engineering. 1st ed. London Longmans, Green and Co., 1899.

10. Dang Van K, Griveau B., and Message O, On a new multiaxial fatigue limit criterion: theory and applications, Biaxial and multiaxial fatigue, EGF 3, Mech. Eng. Publications, London, pp479-496, 1989.

11. P.O.Santacreu, L. Faivre and A.Acher, Life prediction approach for Stainless Steel Exhaust Manifold, SAE Int. J. Passeng. Cars-Mech. Syst. 5(2),2012 . 